\title{
Evaluating Mediterranean diet and risk of chronic disease in cohort studies: an umbrella review of meta-analyses
}

\author{
Cecilia Galbete $^{1,2}$ (1) $\cdot$ Lukas Schwingshackl ${ }^{2,3}$ (D) $\cdot$ Carolina Schwedhelm ${ }^{2,3}$ (D) $\cdot$ Heiner Boeing ${ }^{2,3}$ (D) \\ Matthias B. Schulze $e^{1,2,4}$
}

Received: 30 January 2018 / Accepted: 17 July 2018/Published online: 20 July 2018

(C) The Author(s) 2018

\begin{abstract}
Abstarct
Several meta-analyses have been published summarizing the associations of the Mediterranean diet (MedDiet) with chronic diseases. We evaluated the quality and credibility of evidence from these meta-analyses as well as characterized the different indices used to define MedDiet and re-calculated the associations with the different indices identified. We conducted an umbrella review of meta-analyses on cohort studies evaluating the association of the MedDiet with type 2 diabetes, cardiovascular disease, cancer and cognitive-related diseases. We used the AMSTAR (A MeaSurement Tool to Assess systematic Reviews) checklist to evaluate the methodological quality of the meta-analyses, and the NutriGrade scoring system to evaluate the credibility of evidence. We also identified different indices used to define MedDiet; tests for subgroup differences were performed to compare the associations with the different indices when at least 2 studies were available for different definitions. Fourteen publications were identified and within them 27 meta-analyses which were based on 70 primary studies. Almost all meta-analyses reported inverse associations between MedDiet and risk of chronic disease, but the credibility of evidence was rated low to moderate. Moreover, substantial heterogeneity was observed on the use of the indices assessing adherence to the MedDiet, but two indices were the most used ones [Trichopoulou MedDiet (tMedDiet) and alternative MedDiet (aMedDiet)]. Overall, we observed little difference in risk associations comparing different MedDiet indices in the subgroup meta-analyses. Future prospective cohort studies are advised to use more homogenous definitions of the MedDiet to improve the comparability across meta-analyses.
\end{abstract}

Keywords Mediterranean diet - Chronic diseases · Umbrella review · Meta-analyses · Cohort studies · Heterogeneity

\section{Introduction}

The Seven Countries Study observed in the 1960s a lower cardiovascular mortality in the participating countries around the Mediterranean area [1]. Ancel Keys attributed this observation to the traditional diets such as the high

Lukas Schwingshackl

lukas.schwingshackl@dife.de

1 Department of Molecular Epidemiology, German Institute of Human Nutrition Potsdam-Rehbruecke, Nuthetal, Germany

2 NutriAct - Competence Cluster Nutrition Research BerlinPotsdam, Nuthetal, Germany

3 Department of Epidemiology, German Institute of Human Nutrition Potsdam-Rehbruecke, Nuthetal, Germany

4 Institute of Nutritional Sciences, University of Potsdam, Nuthetal, Germany olive oil consumption in Greece, the high fish intake in the Dalmatian area (Croatia), and the high vegetable intake in Italy. Later on, the dietary components considered to have a beneficial effect on health were combined in one index and published as MedDiet index [2]. Apart from the influence of the Mediterranean diet (MedDiet) on risk of cardiovascular disease (CVD), several metabolic diseases have been studied for a possible favourable role, including type 2 diabetes (T2D), cognitive-related diseases, and different types of cancer in the Mediterranean countries [3-10]. Recently the landmark PREDIMED study has been retracted and republished due to "irregularities in randomisation procedures" $[11,12]$. Similarly to the retracted paper, the new findings showed that the incidence of combined cardiovascular events was lower among those assigned to a MedDiet supplemented with extra-virgin 
olive oil or nuts than among those assigned to a lower-fat diet [12].

The interest in the MedDiet as a whole was not restricted to those countries and thus, the MedDiet has been investigated in many countries that are geographically far from being Mediterranean, e.g. Australia and Japan [13-15]. The observed results have been summarised in several meta-analyses, but the methods used for the estimation of MedDiet adherence in the different study populations were often heterogeneous, implying the creation of many different indices intended to reflect MedDiet. In fact, even though most of the meta-analyses are consistent in their findings, the observed statistical heterogeneity within these varies from low to high (e.g. from $26 \%$ in the study from Jannasch et al. [16] on MedDiet and T2D to $82 \%$ in the meta-analysis on MedDiet and cancer from Schwingshackl et al. [17]). Moreover, the methodological quality and credibility of evidence of these meta-analyses have not been analysed so far.

The creation of nutritional indices is a common tool largely used in the nutritional epidemiology research with the purpose of reflecting the adherence to a dietary pattern, e.g. the MedDiet, in a certain population. These are created by ranking the population according to the intake of foods considered to be in line with, or against, the dietary pattern under study.

Sofi et al. as well as Davis et al. discussed the derived difficulties from the use of different scores measuring MedDiet adherence [18, 19]. They criticised that the use of different population-specific cut-off values for the consumption of the food groups considered to be part of the MedDiet hampered the further clinical and public health applications. But this is not the only discrepancy observed among the different scores; both authors mentioned also the inconsistencies observed in the classification of the food groups. However, this point has not been deeply investigated and could be one of the reasons for the high statistical heterogeneity found in several of the published meta-analyses. Thus, by the present complementary umbrella review, in a first step, we aimed to evaluate the methodological quality and the credibility of evidence generated by all available meta-analyses evaluating the association between adherence to a MedDiet and major chronic diseases (T2D, CVD, cancer and cognitive-related disorders) in cohort studies. In a second step, we aimed to enumerate and characterize the different definitions used to assess adherence to the MedDiet in the studies gathered in the meta-analyses, and to emulate the associations on chronic diseases with the different dietary MedDiet adherence indices.

\section{Methods}

This manuscript was drafted in adherence to the recommendations of the 'Preferred Reporting Items for Systematic reviews and Meta-Analyses' (PRISMA) checklist [20].

The methodological approach of this umbrella review is based on previous published umbrella reviews, which focused on nut and garlic intake and risk of CVD [21, 22], and is next explained.

\section{Data sources and search strategy}

PubMed (from inception until 27th March 2018) and Embase (from inception until 27th March 2018) was searched for meta-analyses published in English language using following search terms: (Mediterranean[tiab]) AND (cardiovascular[tiab] OR coronary[tiab] OR myocardial[tiab] OR stroke[tiab] OR mortality[tiab] OR cancer[tiab] OR "neoplastic disease"[tiab] OR tumor[tiab] OR diabetes[tiab] OR “cognitive decline"[tiab] OR cognition[tiab] OR dementia[tiab] OR Alzheimer disease[tiab]) AND (meta-analysis[tiab]). Additionally, reference lists of the included meta-analyses were verified for further relevant studies as well.

\section{Inclusion criteria}

Studies were included in this umbrella review if they met all of the following criteria: (1) meta-analysis of cohort studies, (2) evaluating the association of scores used for assessing adherence to a MedDiet or considered by the authors as reflecting a MedDiet type diet, (3) study population: $\geq 18$ years, (4) study endpoints include overall cancer mortality and/or incidence, CVD or coronary heart disease (CHD) mortality and/or incidence, stroke, myocardial infarction (MI), acute myocardial infarction (AMI) type 2 diabetes, Alzheimer's disease (AD), mild cognitive impairment (MCI), or dementia.

\section{Methodological quality}

The methodological quality was evaluated using a modified version of the AMSTAR (A MeaSurement Tool to Assess systematic Reviews) [23] checklist, which has been recently established to evaluate the methodological quality of meta-analyses and systematic reviews on the Mediterranean diet and CVD outcomes and is based on 14 items (maximum score of 22) [24]. These are grouped within four different domains; (1) "a priori design", which includes two questions, (2) Literatures search and duplicate effort, which includes five different questions, (3) coding of studies, including two questions, and (4) analysis and 
interpretation, which includes four different questions. The original AMSTAR checklist has been previously used to choose high quality systematic reviews and meta-analysis to build the Dietary Guidelines for Americans 2015-2020 [25].

\section{Credibility of the evidence}

To evaluate credibility of evidence for the association between adherence to MedDiet and risk of the included outcomes we applied the NutriGrade scoring system (max 10 points) which comprises the following items for cohort studies [26]: (1) risk of bias/study quality/study limitations, (2) precision, (3) heterogeneity, (4) directness, (5) publication bias, (6) funding bias, (7) effect size, and (8) doseresponse. Based on this scoring system we recommend four categories to judge credibility of meta-evidence: high, moderate, low, and very low taking into account the following cut-points: $\geq 8$ points (high meta-evidence), 6-7.99 points (moderate meta-evidence), 4-5.99 (low meta-evidence), and 0-3.99 (very low meta-evidence).

\section{Identification of different MedDiet scores}

Within the meta-analyses included in this study the different scores used in the primary studies were carefully evaluated. The nine food groups referred to by Trichopoulou et al. [27], and usually quoted for the creation of the MedDiet score were considered as the basis (fruit, vegetables, legumes, cereals, meat, dairy products, fish, alcohol and, healthy fats), and for each primary study we carefully identified the foods reported to be included within the different food groups. Thus, the scores were considered to be different when: (1) different food groups were included, (2) food groups were comprised of different food items, and (3) different specific cut-off values within the food items were applied. This last point was particularly relevant for the different cut-off values used to define "moderate alcohol intake".

\section{Statistical analysis}

If at least two cohort studies were included in a metaanalysis for at least two specific MedDiet adherence scores identified (e.g. tMedDiet, aMedDiet, sMedDiet) a new meta-analysis was carried out to estimate and compare the associations between these scores for the included outcomes. These new meta-analyses were performed by combining the multivariable adjusted RRs, HR of the highest compared with the lowest MedDiet adherence category, or 2-point increase in MedDiet adherence score based on a random effects model using the DerSimonian-Laird method, which incorporated both within and between study variability [28]. To evaluate the weighting of each study, the standard error for the logarithm HR/RR/OR of each study was calculated and regarded as the estimated variance of the logarithm $\mathrm{HR} / \mathrm{RR} / \mathrm{OR}$, using an inverse variance method [28].

To detect discrepancies between the different types of MedDiet adherence scores for an outcome a test for subgroup differences was performed based on a random effects model (fixed effects model used for the sensitivity analysis).

For the summary random effects, we estimated for each meta-analysis the $95 \%$ prediction interval (PI), which further accounts for the degree of between-study heterogeneity and gives a range for which we are $95 \%$ confident that the effect in a new study examining the same association lies within [29].

All analyses were conducted using the Review Manager by the Cochrane Collaboration (version 5.3) and Stata 14.2 (Stata-Corp, College Station, TX. USA).

\section{Results}

The study characteristics of the meta-analyses are summarized in Table 1. A total of 14 publications reporting 27 meta-analyses on the association of the MedDiet with the risk of any of the major chronic diseases (T2D, CVD, cancer, or cognitive-related diseases) were included in the present umbrella review [16, 17, 19, 30-40]. Among all the meta-analyses 70 primary studies were included [2, 7, 13, 27, 41-106]. Several different endpoints have been evaluated: T2D, CVD incidence and/or mortality, CHD incidence, different types of stroke incidence and/or mortality, MI incidence, MCI incidence, AD incidence, and dementia incidence. Four meta-analyses were found evaluating the association between adherence to the MedDiet and risk of T2D [16, 30, 31, 40], among which 11 primary studies were considered $[7,43,46,50,61,74$, 76, 79, 82, 83, 98]. Comparing the highest versus lowest adherence category an inverse association between $13 \%$ (RR $0.87,95 \%$ CI $0.82,0.97$ ) and $23 \%$ (RR $0.77,95 \%$ CI $0.66,0.89)$ for the risk of T2D was observed. Regarding the different CVD endpoints a total of 12 meta-analyses within 5 publications were identified [19, 32-35], and within these 31 primary studies were included $[2,13,41,44,47,49,51$, $52,56,59,60,67,71,72,75,77,78,80,85-87,89-93$, $96,100,103-105]$. A 2-point increase in adherence to the MedDiet score was associated with a $10 \%$ (RR 0.90, 95\% CI $0.86,0.94)$ lower risk of CVD incidence/mortality $[19,34]$. Comparing the highest versus lowest category of adherence to the MedDiet the risk of CVD was reduced by approximately $19 \%$ (RR $0.81,95 \%$ CI $0.74,0.88$ ) to $27 \%$ 
(RR 0.73, 95\% CI 0.66, 0.80). Similar results were reported for CHD (RR 0.72, 95\% CI 0.60, 0.86), MI (RR 0.67, 95\% CI 0.54, 0.83), AMI (RR 0.74, 95\% CI 0.66, 0.83), and stroke (RR $0.77,95 \%$ CI $0.67,0.90)$. No association was observed between adherence to the MedDiet and haemorrhagic stroke. Regarding overall cancer incidence and/or mortality four meta-analyses were identified within three publications [17, 19,36], and within these a total of 27 primary studies were identified $[27,42,45,48$, 53-55, 57-59, 62, 68-70, 72, 73, 75, 78, 80, 84, 94, 96, 97, 99-102]. Two meta-analyses considering overall cancer mortality and one meta-analysis including overall cancer incidence were found [17, 36], whereas in another metaanalysis conducted by Sofi et al. [19] cancer mortality and incidence were combined. Comparing the highest versus lowest adherence to MedDiet category a 14\% (RR 0.86, $95 \%$ CI $0.81,0.91$ ) (4\% reduction for cancer incidence) reduced risk of cancer mortality was reported, whereas a 2-point increase in the MedDiet score was associated with a 5\% (RR $0.9595 \%$ CI 0.93, 0.97) reduced risk of cancer mortality/incidence. Regarding cognitive-related disorders three studies meta-analysed the observed effects of MedDiet with different outcomes: MCI, AD and dementia [37-39]. A total of 6 meta-analyses were conducted [37-39]. Comparing highest versus lowest category of adherence to the MedDiet up to $31 \%$ (RR 0.69, 95\% CI $0.57,0.84)$ risk reduction for MCI was observed and $40 \%$ (RR 0.60 , 95\% CI $0.48,0.77$ ) reduction for AD. No association was observed for incident dementia.

Almost all included meta-analyses showed a significant inverse association between higher adherence to a MedDiet and risk of chronic diseases. Estimating 95\% prediction intervals, however, the null value was excluded only in some of the associations (CVD incidence, CVD incidence/mortality, CHD/AMI incidence mortality, unspecified stroke incidence/mortality, $\mathrm{AD}$ incidence, and MCI incidence). This implies that most meta-analyses indicated high degrees of statistical heterogeneity and/or were based on a limited number of studies.

\section{Methodological quality}

In total, the overall methodological quality of the included meta-analyses was rated as moderate (Table 1). On average, the meta-analyses achieved a mean of 16.5 points ( $75 \%$ of the maximum score).

\section{Credibility of the evidence}

The NutriGrade credibility of evidence judgement varied between low (low confidence for the effect estimate: further research provides important information on the confidence and likely change the effect estimate) and moderate (moderate confidence for the effect estimate: further research could add information on the confidence and may change the effect estimate).

\section{Description of the different scores}

A total of 70 primary studies were included within the 27 meta-analyses, where 34 different scores meant to reflect the MedDiet were applied [2, 7, 13, 27, 41-106]. A detailed description of the different definitions is shown in Table 2. Within the 34 different definitions gathered from the included studies, two main ones could be extracted; the first one made reference to the definitions derived from the one created in 2003 by Trichopoulou et al. [27] (tMedDiet), which, after the careful evaluation was considered as different from the first one used by Trichipoulou et al. [2]. The Trichopoulou definition from 2003 included nine food groups, five were postulated to be in line with it (vegetables, fruits and nuts, cereals, legumes, and fish), and two were in disagreement with it (dairy products and meat). Alcohol intake in moderation was also considered as part of the MedDiet, as well as a higher intake of monounsaturated fats (MUFA) in relation to saturated fats (SFA). Fourteen studies out of the 70 identified were using this definition to assess adherence to the MedDiet [7, 27, 41-52]. Nine other definitions, used in 18 studies, were relatively similar to this one (labelled from tMedDiet 1 to tMedDiet 9) [13, 53-68, 106]. The differences among these dietary pattern scores were observed in the cut-off values considered to define moderate alcohol intake as well as in how healthy fat intake was reflected. Regarding this last point two of these definitions, tMedDiet 4 and 5 [13, 58-62], considered intake of olive oil instead of the MUFA: SFA ratio. This modification has been commonly used in those studies conducted in non-Mediterranean countries, where the intake of MUFA could be mainly represented by the fat intake from meat rather than olive oil. Another variation of this definition, tMedDiet 1 [53-55], included the intake of polyunsaturated fatty acids (PUFA) together with MUFA.

The second main definition observed referred to the one created by Fung et al. [71], the alternative MedDiet index (aMedDiet). The authors modified the original score created by Trichopoulou et al. by considering some eating behaviours that were associated with lower risk of chronic disease. Thus, the authors separated into two different groups fruits and nuts, eliminated the dairy group, included whole grain products only, as well as only red and processed meat. Nine studies used this definition and five other studies used a definition relatively similar to this one [69-77]. The main difference was observed in how alcohol intake in moderation was defined, and also one of these 


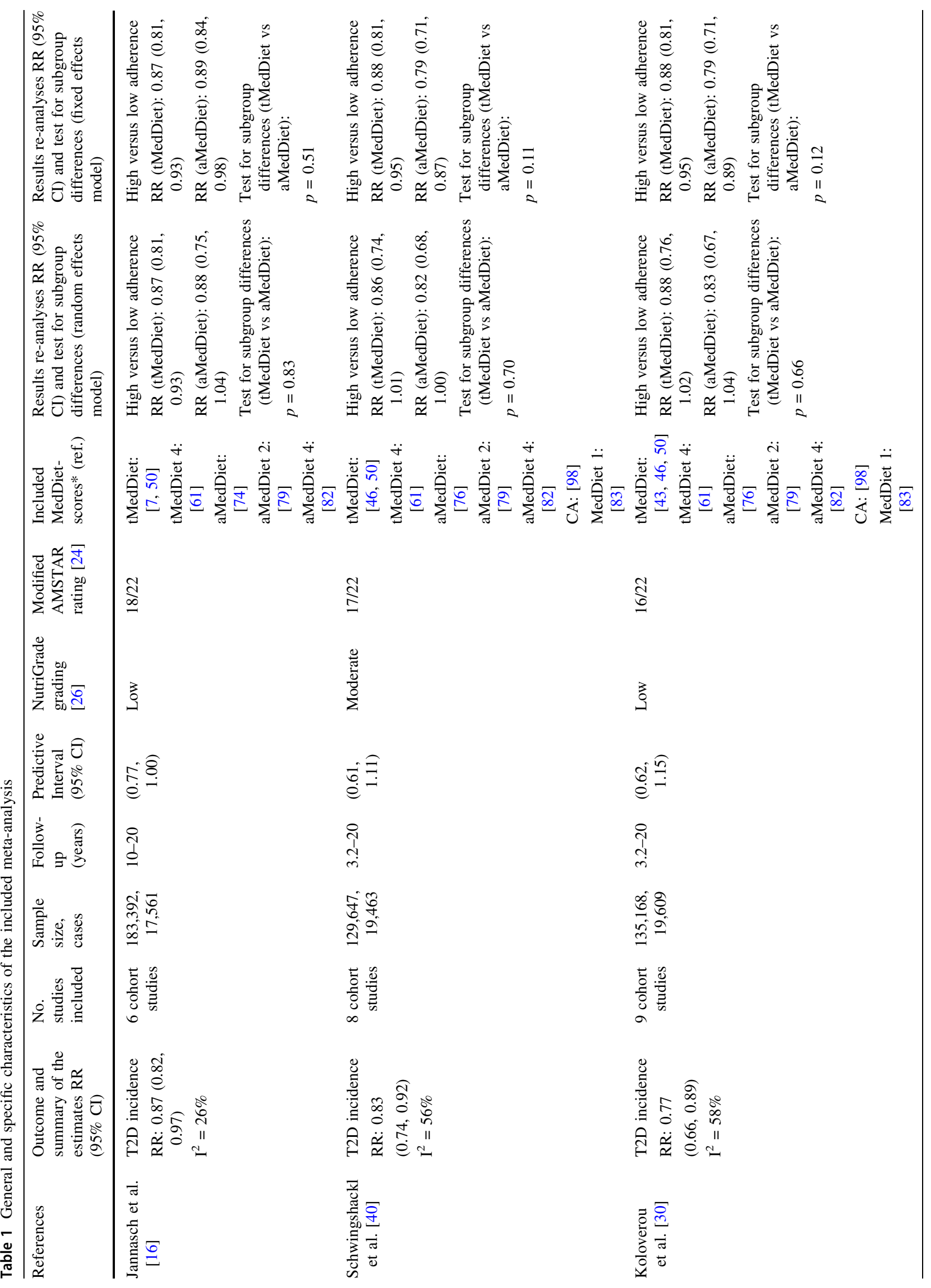




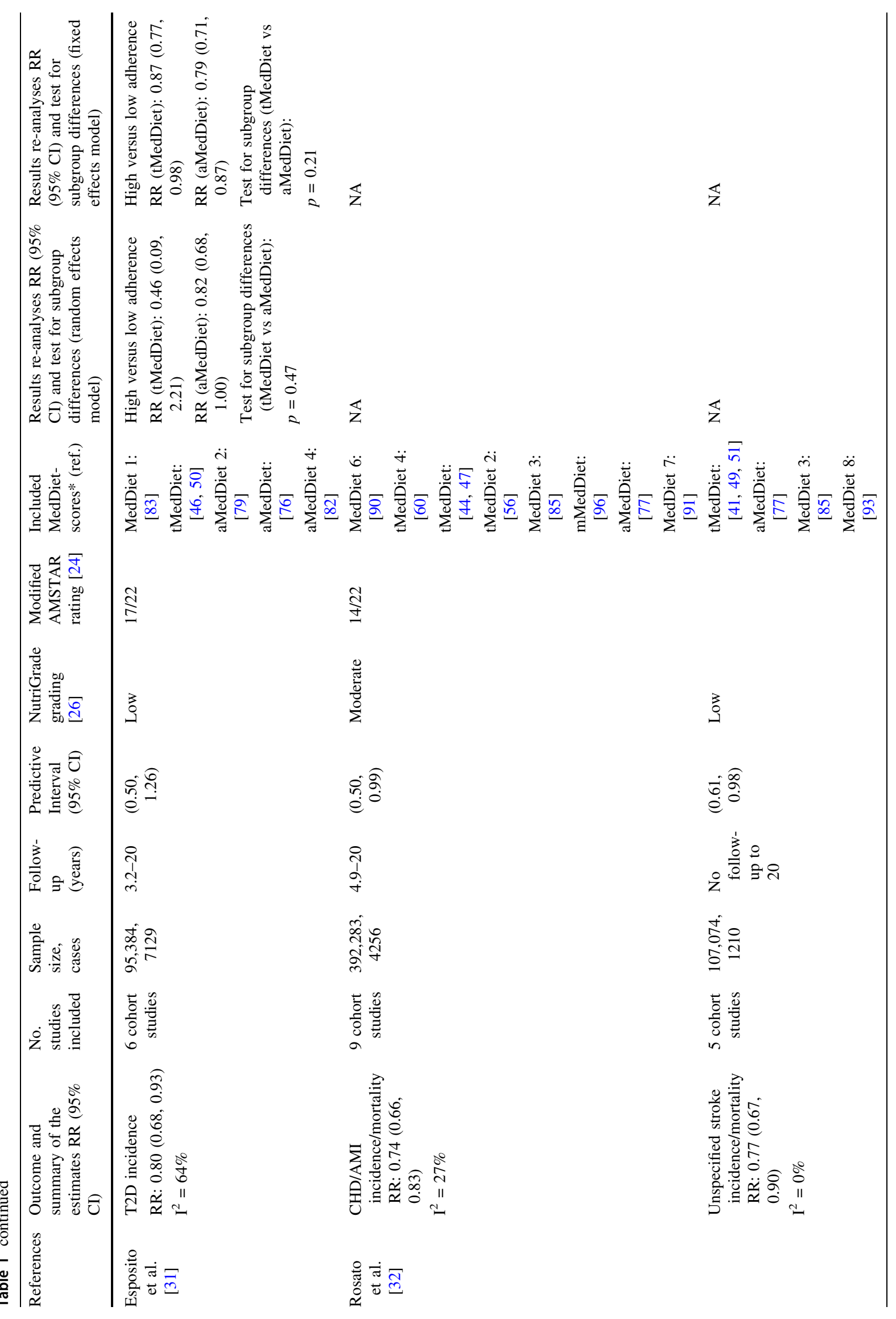




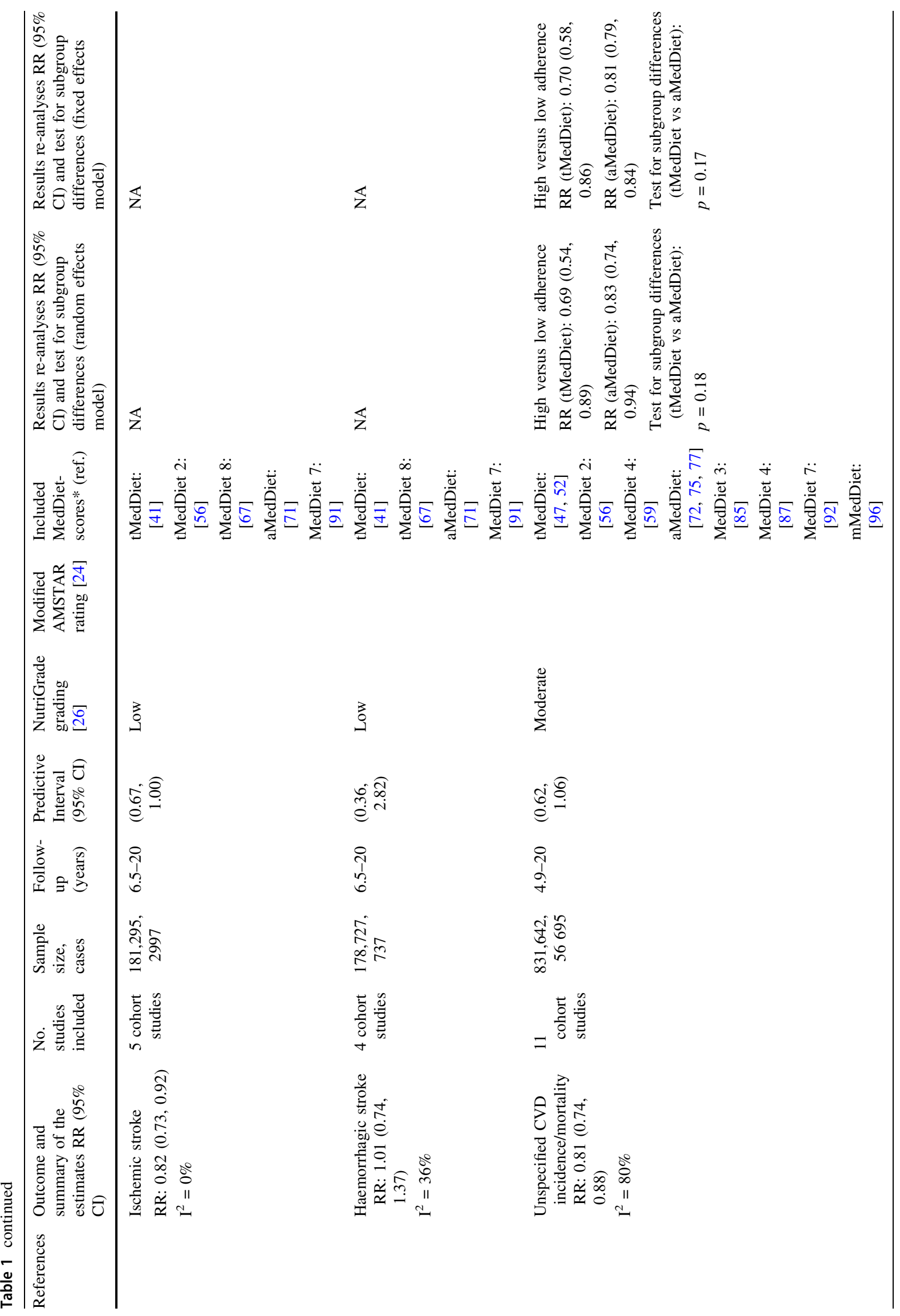




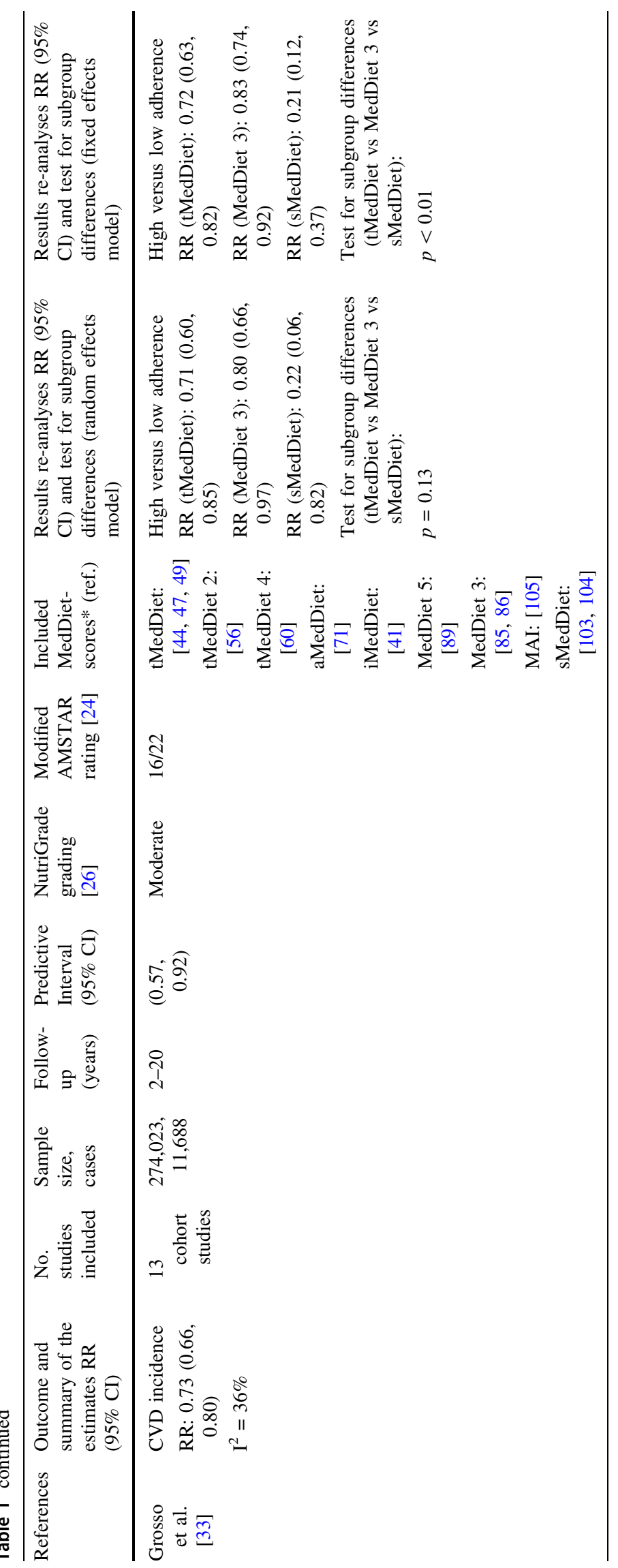




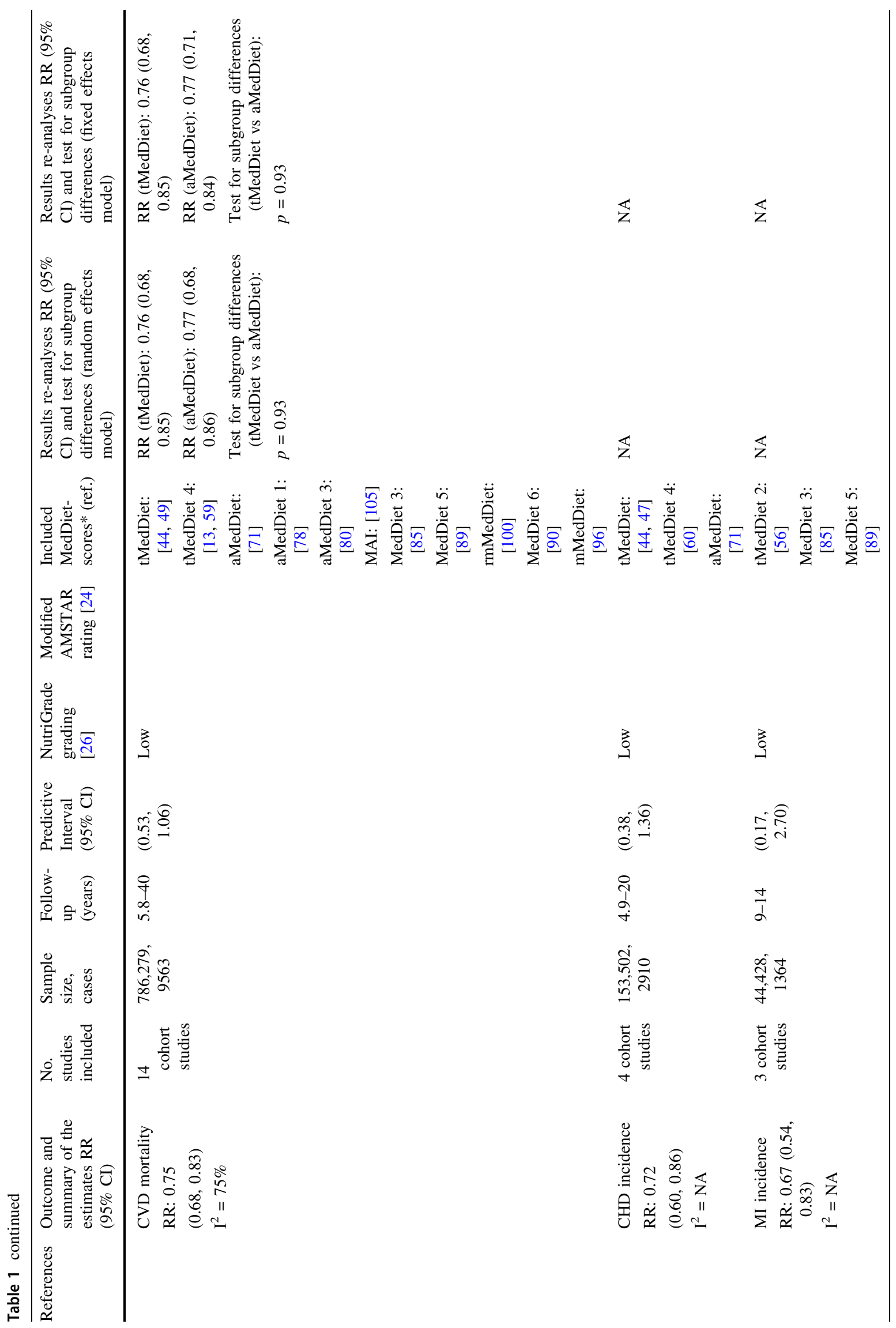




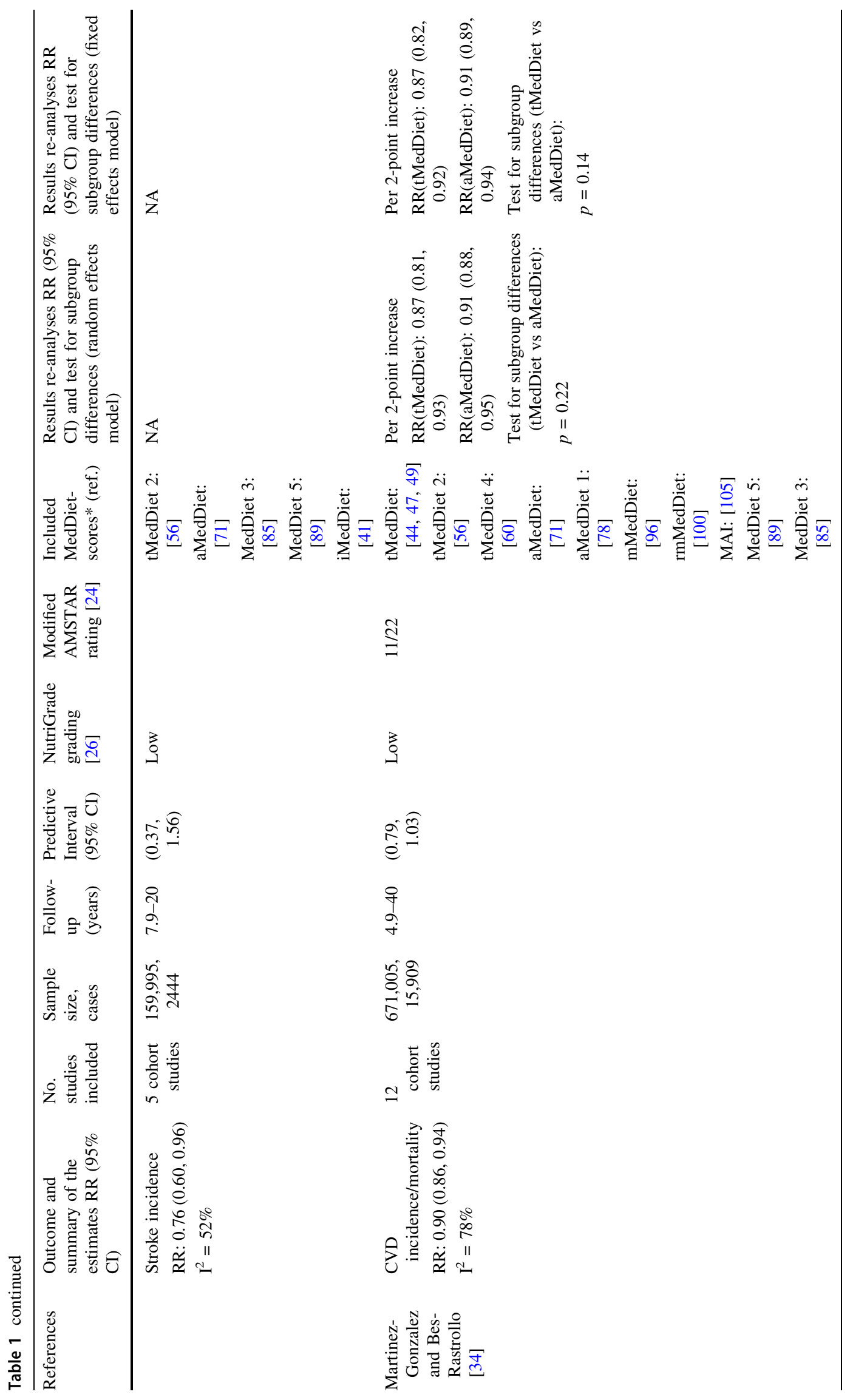




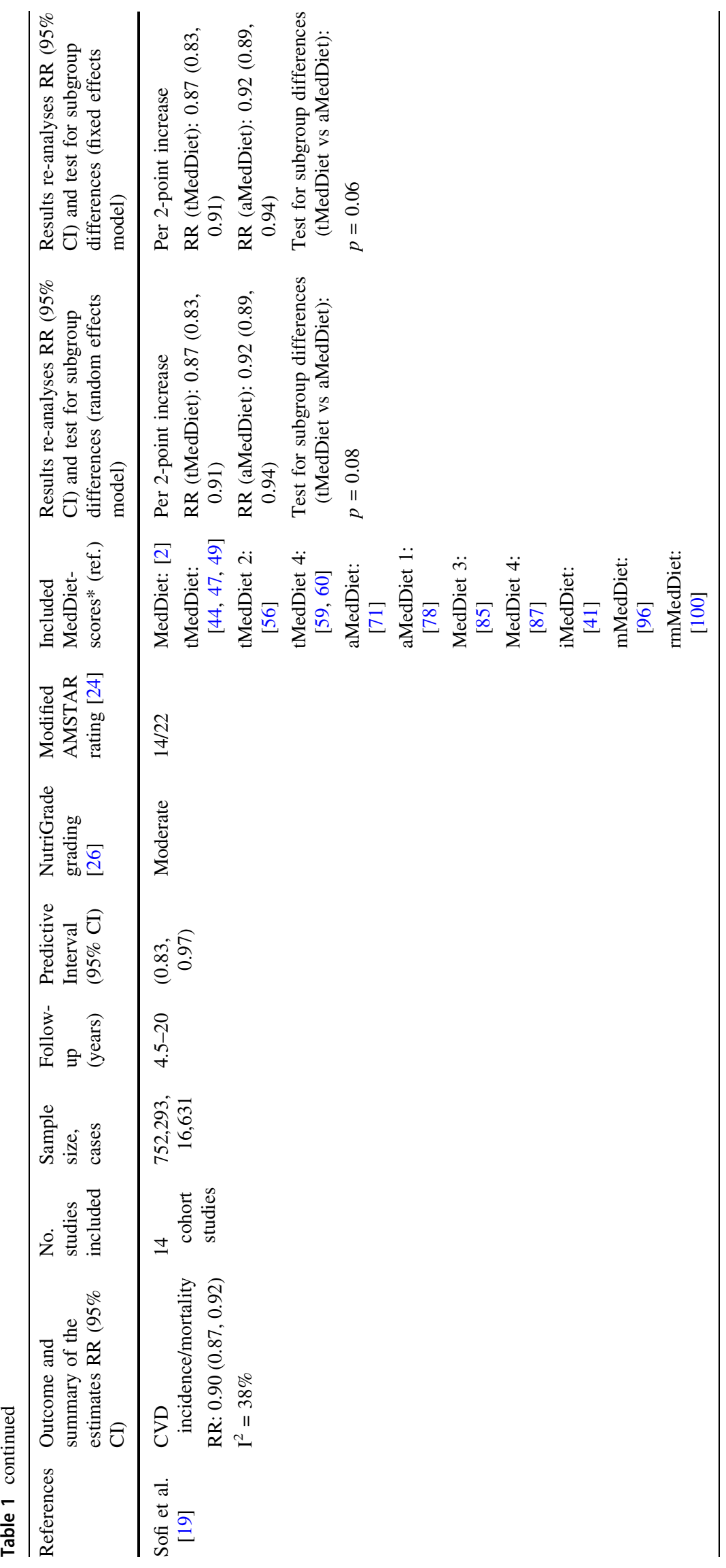




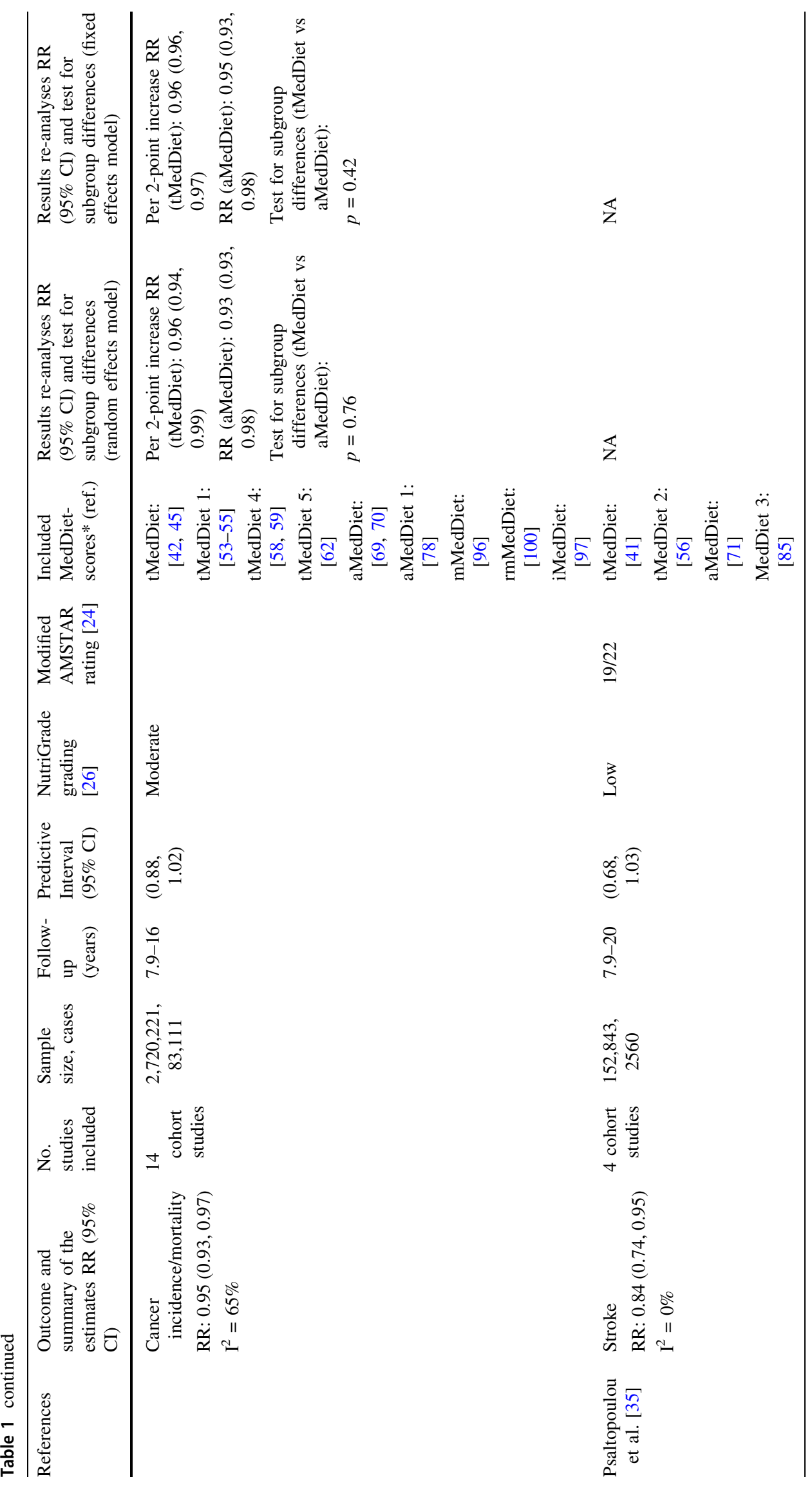




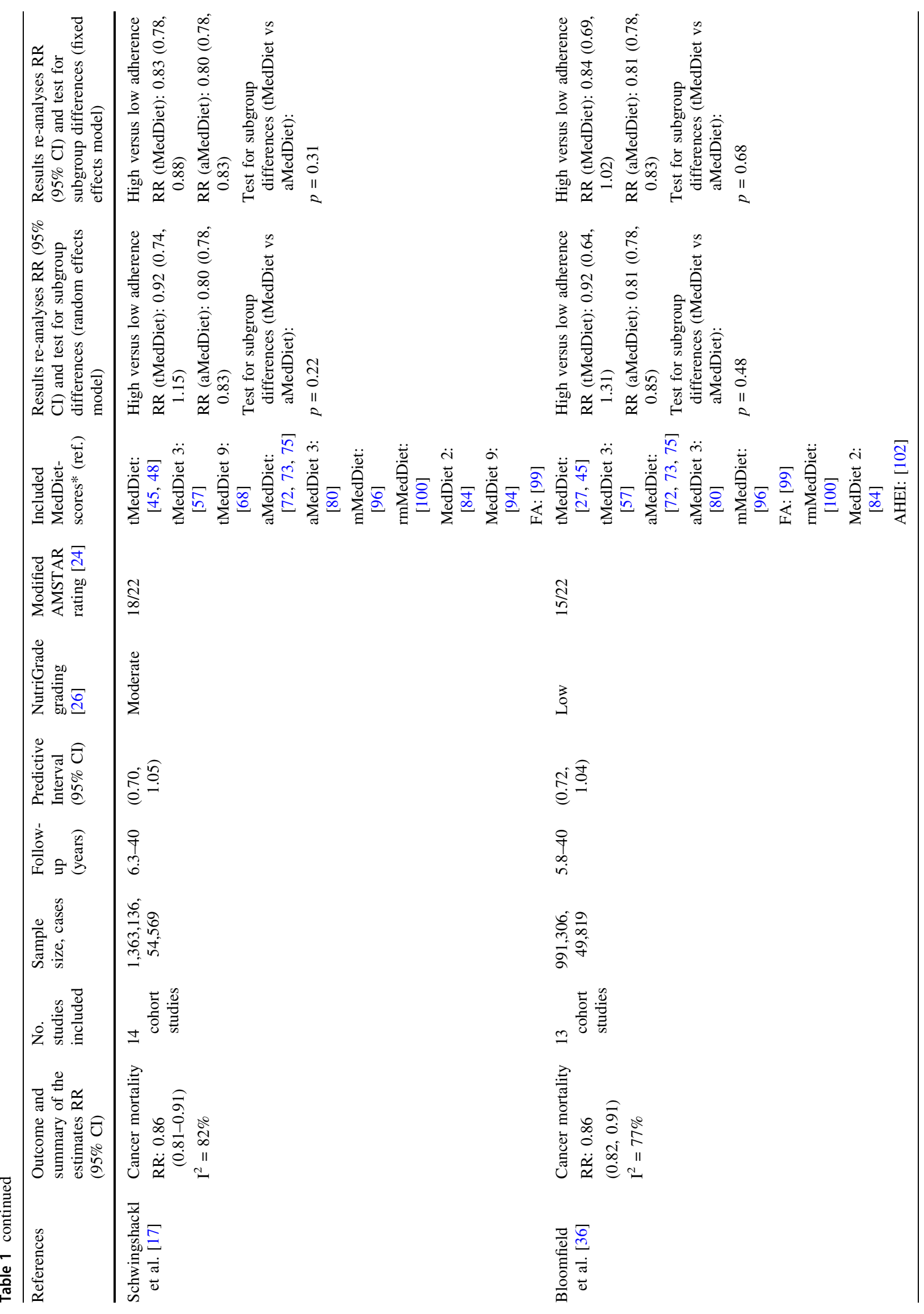




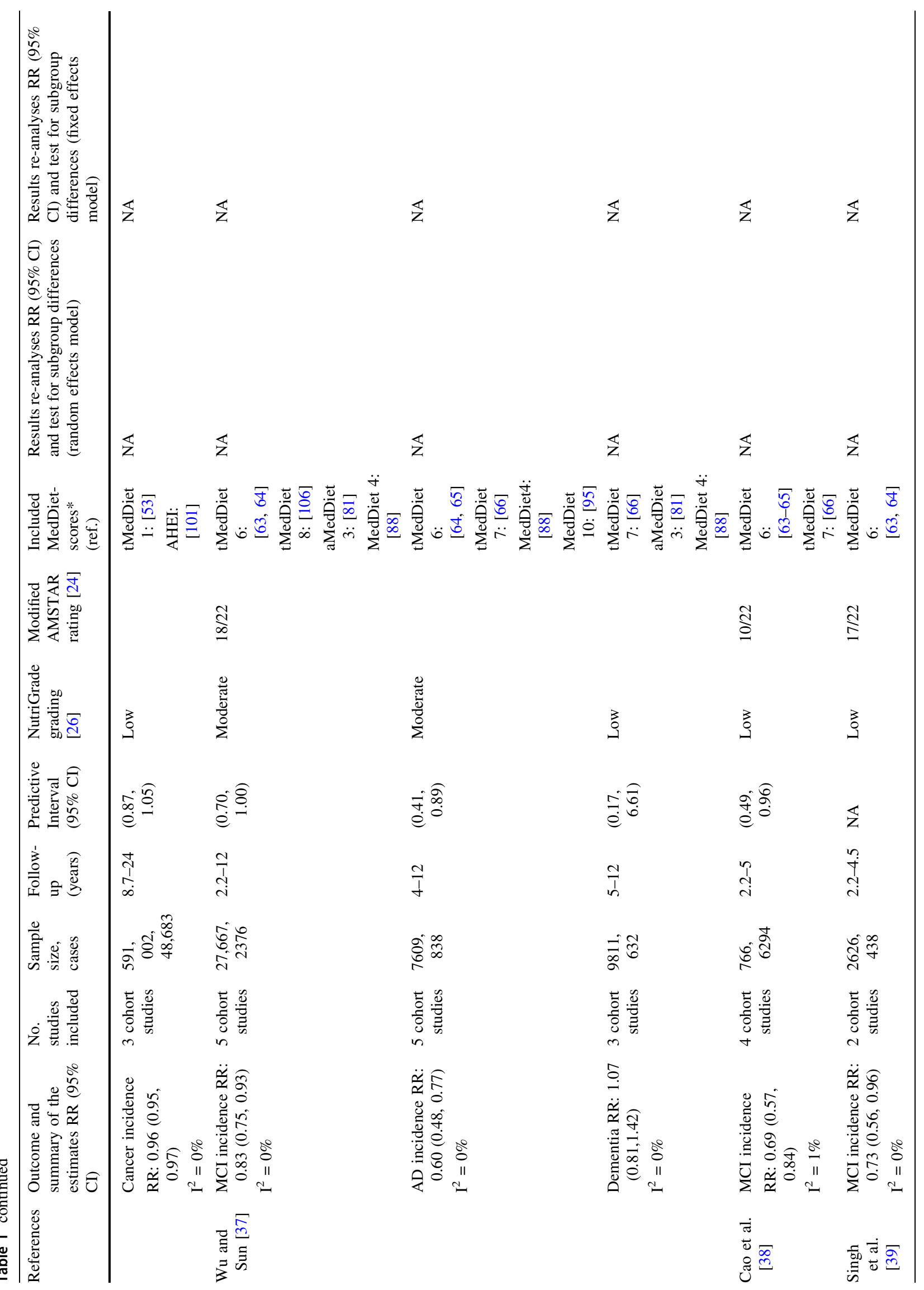


definitions, aMedDiet 4 [82], included the food group high fat-dairy products as not being in line with the MedDiet.

Apart from these two main groups of definitions we identified 16 other scores used to assess MedDiet adherence in 24 reports [41, 83-105]. A great variability was observed among these different definitions (see Table 2). In addition, some of the meta-analyses here evaluated included also studies in which MedDiet adherence specifically was not intended to be assessed. This is for example the case of the meta-analyses from Bloomfield et al. [36] evaluating the effects of the MedDiet on cancer mortality and incidence. There, the authors also included two reports in which the Alternative Healthy Eating Index (AHEI) was assessed and not the MedDiet [101, 102]. In their metaanalysis on cancer mortality Bloomfield et al. also included the study of Menotti et al. [99], in which two dietary patterns were identified by means of factor analysis. Particularly, the authors observed a dietary pattern characterized by high consumption of bread, pasta, potatoes, vegetables, fish, and oil and by lower consumption of milk, sugar, fruit, and alcoholic beverages and argued this was similar to the MedDiet dietary pattern. Similarly, two of the meta-analyses here identified evaluating the effects of MedDiet on the onset of T2D [30, 40] included the study of Brunner et al. [98], in which dietary patterns were obtained by cluster analysis. In this study one of the clusters identified was strong and positively correlated with the intake of fruit, vegetables, rice, pasta, and wine, and thus named Mediterranean-like cluster.

\section{Test for subgroup differences comparing different types of MedDiet adherence scores}

Several of the included meta-analyses reported moderate to high statistical heterogeneity, which could be related to the different indices applied. Once we identified the different scores used in the primary studies and considered these as similar enough, if at least two cohort studies were included in a meta-analysis for at least two different MedDiet scores, we combined the studies applying similar scores in a new meta-analysis and tested for possible subgroup differences in between the different scores.

Comparing the tMedDiet versus the aMedDiet score suggested no evidence for subgroup differences $(p>0.10)$ for T2D as outcome in the random effects model (Table 1). In the meta-analysis by Bloomfield et al. on cancer mortality, an inverse association was observed with aMedDiet (RR $0.81,95 \%$ CI 0.78, 0.85), while no association with the tMedDiet was found (RR 0.92, 95\% CI 0.64, 1.31). However, as in the re-analysis of the work from Sofi et al. for cancer mortality/incidence, no evidence for subgroup differences were observed in the study from Bloomfield et al. Regarding CVD, a marginal difference in the 
subgrouping (test for subgroup difference $p=0.06$ ) was observed when reanalysing the meta-analysis by Sofi et al. [19], where the tMedDiet showed a stronger inverse association (RR $0.87,95 \%$ CI $0.83,0.91$ ) compared to studies using the aMedDiet score (RR 0.92, 95\% CI 0.89, 0.94). Nevertheless, no statistically significant subgroup differences were observed in any of the other meta-analyses. The fixed effects sensitivity analyses confirmed mainly the results of the random effects meta-analysis.

Unfortunately, in the case of the meta-analyses on cognitive-related diseases it was not possible to test for sub-group differences due to the small number of studies included.

\section{Discussion}

In this umbrella review of meta-analyses, we summarized the findings from prospective cohort studies and investigated the different scores used to assess MedDiet and their implications on the risk of major chronic diseases (T2D, CVD, cancer and cognitive-related diseases). We observed that a higher adherence to the MedDiet was associated with lower incidence of T2D, lower incidence/mortality of CVD, and lower incidence/mortality of cancer; the credibility of this evidence ranged from low to moderate. Low credibility of the evidence implies that the confidence in the effect estimate was low and that further research will provide important evidence on the confidence and likely change the effect estimate, while moderate credibility means that further research could add evidence on the confidence and may change the effect estimate [26]. Two scores assessing adherence to the MedDiet were manly applied in cohort studies (tMedDiet and aMedDiet). Overall, we observed little difference in risk associations comparing tMedDiet versus aMedDiet indices in the subgroup meta-analysis. In the meta-analysis by Sofi et al. [19], which assessed the effect of the MedDiet on the risk of CVD incidence/mortality, some differences were observed; in this case, both MedDiet scores associated with lower risk, but the effects observed for the tMedDiet score were stronger.

\section{Mediterranean diet scores and health associations}

Within the large variety of indices attempting to reflect adherence to the MedDiet two scores could be identified which were applied more frequently; the tMedDiet used in 32 studies [7, 13, 27, 41-68, 106], and the aMedDiet used in 14 studies [69-82]. Nineteen other definitions were found within the remaining 24 studies [41, 83-105]. These were very disperse; from dietary patterns derived by exploratory methods [98, 99] to other scores not explicitly created to assess MedDiet, such as the Alternative Healthy Eating Index [101, 102].

The tMedDiet score was used for the first time by Trichopoulou et al. [27] in the EPIC-Greece cohort in 2003, while the aMedDiet score was created and used for the first time by Fung et al. [70] in the Nurses' Health Study. This second one was a literature-updated version according to published evidence. As stated before, for most of the analyses here conducted, similar associations were observed when applying one or the other score. In the meta-analysis by Bloomfield et al. differences in the estimates were observed but the test for subgroup differences was not significant. These observed differences could be due to the selection of healthier items included in the aMedDiet score compared to the tMedDiet. This is the case, for example, of whole grains; the most recent metaanalyses observed an inverse dose-response association of whole grains with cancer mortality [107, 108]. The evidence regarding the health implications of dairy products is controversial. A recent meta-analysis observed in a nonlinear dose-response model that low intake of total dairy products could be protective against cancer-related deaths [109]. Concerning meat and processed meat, the World Cancer Research Fund International recommends an average consumption under $300 \mathrm{~g}$ a week, and to limit as much as possible the intake of processed meat [110]. The same report stated that processed meat has been particularly associated with an increased risk of colorectal and stomach non-cardia cancers. Finally, the inclusion of two food groups for fruits and nuts instead of combining them into one attributes a higher weight of these food items presumed to have a beneficial effect on health. These two food groups, as well as whole grains, are rich in fibre, nutrient particularly associated with lower risk of colorectal cancer [111]. In any case, our analyses are restricted to overall cancer mortality; the broad consideration of overall cancer and this approach could complicate possible conclusions and interpretations due to the different nature and aetiology of the different cancer sites. Still, no difference has been observed for T2D and CVD even though foods like whole grains and red meat have been also shown to be associated with these diseases [112-116].

Some other limitations should be mentioned. In the first place, our analyses have been restricted to the ones already performed by the authors and this could complicate the comparisons. For example, some of the authors combined incidence and mortality in one outcome while other preferred to assess these separately. Moreover, the definitions for the scores here identified were restricted to the ones previously identified by the authors conducting the metaanalyses we have here evaluated. Thus, other scores used to assess adherence to the MedDiet could not have been 


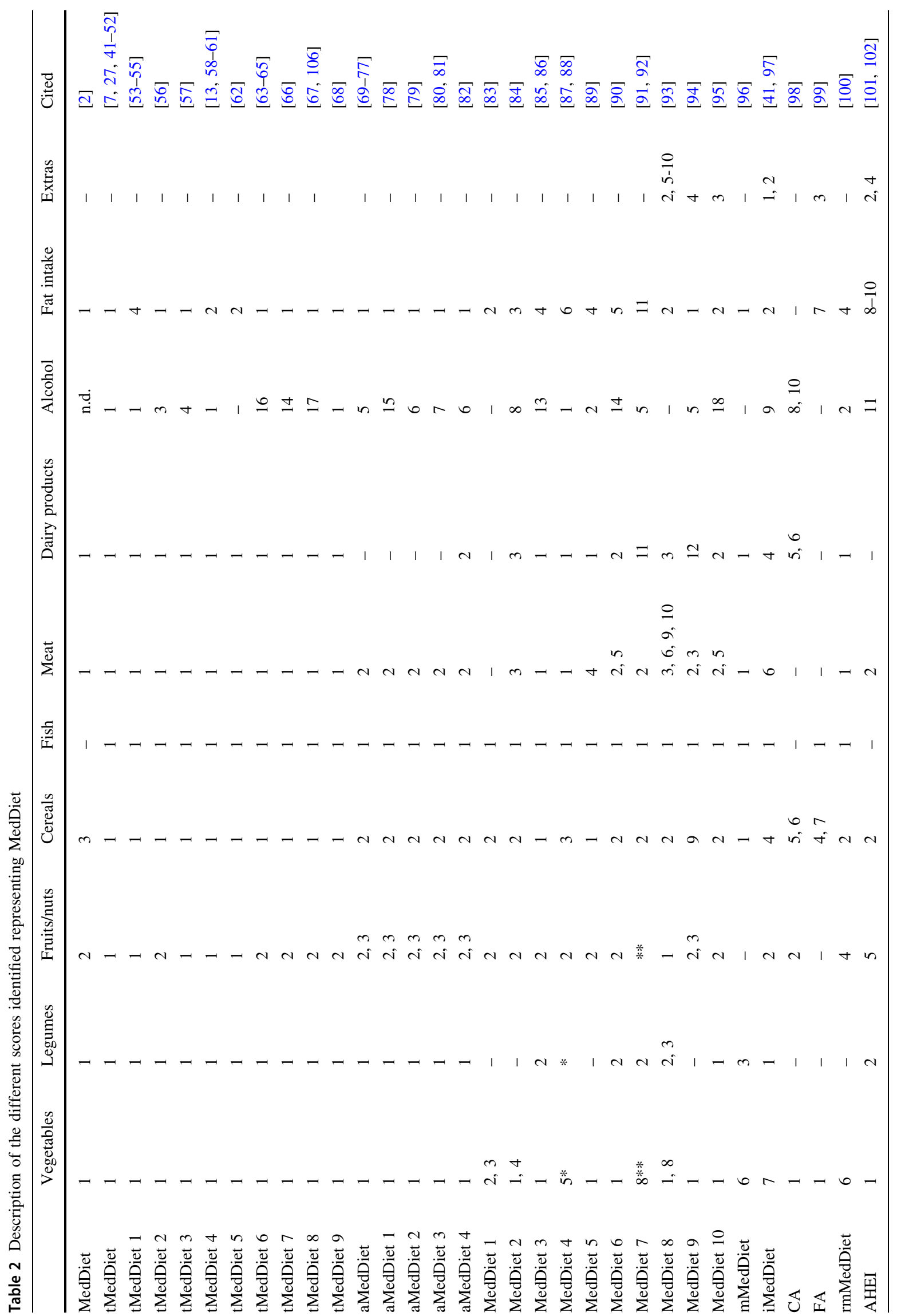




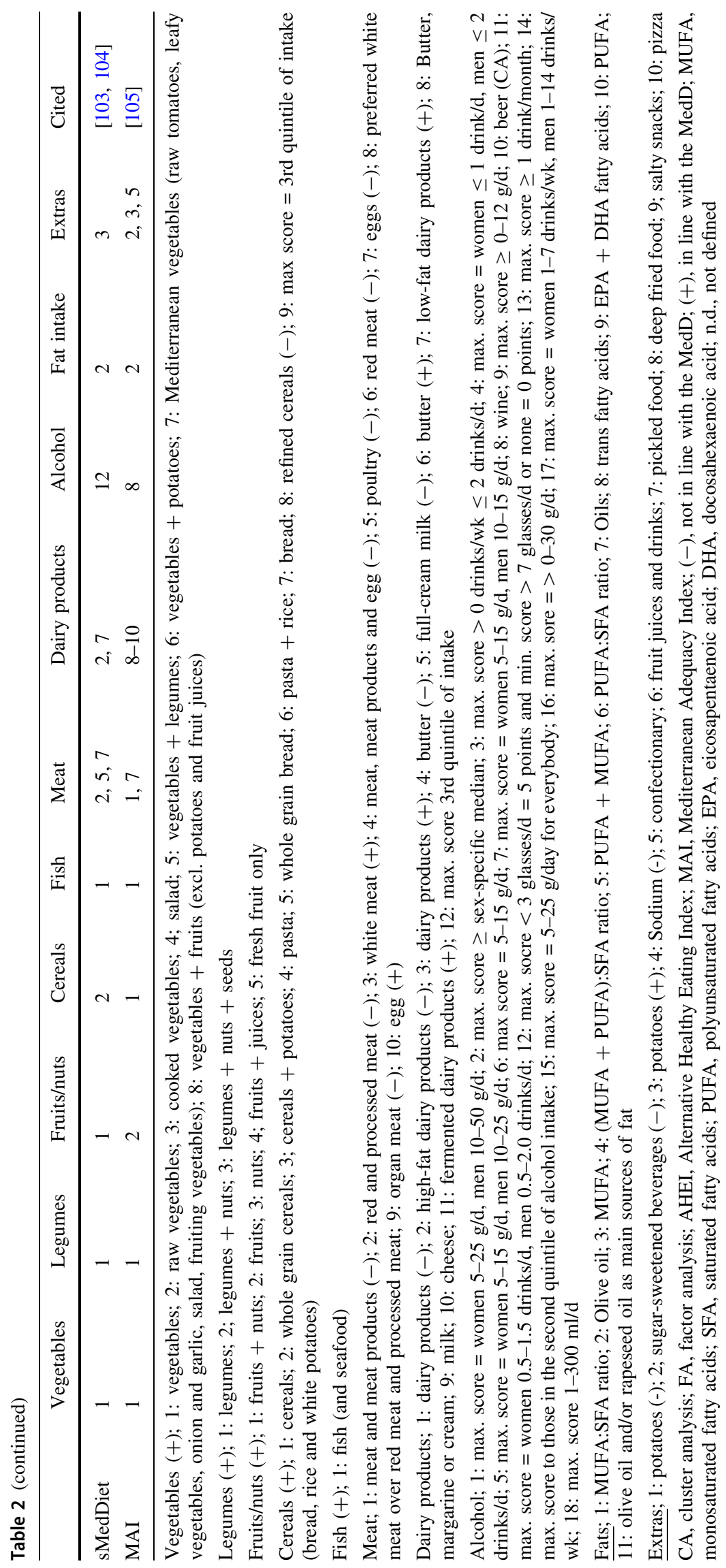


identified. This is the case, for example of the Mediterranean diet pyramid [117]. On the other hand, other sources of heterogeneity due to the construction of the scores have not been evaluated here. Moreover, umbrella reviews are limited by their primary objective. In our case we targeted meta-analyses on prospective observational studies and thus, no randomized controlled trials were included. Also, only studies included within the identified meta-analyses have been here evaluated; any other potentially relevant study could not have been included. A part from this, other interesting and possible sources of differences on the credibility and the heterogeneity observed in the metaanalyses (e.g. country affiliations of authors, year of publication) has not been evaluated within this work. For example, difference in the number of cohort studies included in the meta-analyses for a certain endpoint can be observed; this is due to the inclusion criteria restriction, some meta-analyses only included studies with healthy participant at baselines, like Jannasch et al. [16] while other did not consider this [28].

\section{Conclusion}

In summary, most included meta-analyses reported an inverse association between high adherence to MedDiet and risk of chronic disease; however, the credibility of evidence was rated low to moderate. The present umbrella review shows considerable heterogeneity in the assessment of adherence to the MedDiet, which limits the comparability among primary studies. Two main scores [Trichopoulou MedDiet (tMedDiet) and alternative MedDiet (aMedDiet)] have been identified as the most used and we encourage researchers to use one of these two definitions when assessing adherence to the MedDiet if possible in order to not compromise further comparability among studies. The use of other scores would be justified in case these would better reflect the MedDiet for the purpose of the research. For most of the outcomes here evaluated we did not observe major differences in the use of one or the other of these two scores, nevertheless, some differences were observed for cancer mortality, fact that could be due to the betterment of the aMedDiet with regard to the tMedDiet according to the literature evidence.

Funding This work was supported by NutriAct - Competence Cluster Nutrition Research Berlin-Potsdam funded by the German Federal Ministry of Education and Research (FKZ: 01EA1408A-G). The funders had no role in study design, data collection and analysis, decision to publish, or preparation of the manuscript.

\section{Compliance with ethical standards}

Conflict of interest The authors declare that they have no conflict of interest.

Open Access This article is distributed under the terms of the Creative Commons Attribution 4.0 International License (http://creative commons.org/licenses/by/4.0/), which permits unrestricted use, distribution, and reproduction in any medium, provided you give appropriate credit to the original author(s) and the source, provide a link to the Creative Commons license, and indicate if changes were made.

\section{References}

1. Menotti A, Kromhout D, Blackburn H, et al. Food intake patterns and 25-year mortality from coronary heart disease: crosscultural correlations in the Seven Countries Study. Eur J Epidemiol. 1999;15(6):507-15. https://doi.org/10.1023/A: 1007529206050.

2. Trichopoulou A, Kouris-Blazos A, Wahlqvist ML, et al. Diet and overall survival in elderly people. BMJ (Clin Res Ed). 1995;311(7018):1457-60.

3. Toledo E, Salas-Salvado J, Donat-Vargas C, et al. Mediterranean diet and invasive breast cancer risk among women at high cardiovascular risk in the PREDIMED trial: a randomized clinical trial. JAMA Intern Med. 2015;175(11):1752-60. https://doi.org/10.1001/jamainternmed.2015.4838.

4. Stojanovic J, Giraldi L, Arzani D, et al. Adherence to Mediterranean diet and risk of gastric cancer: results of a casecontrol study in Italy. Eur J Cancer Prev Off J Eur Cancer Prev Org. 2017;26(6):491-6. https://doi.org/10.1097/CEJ.000000000 0000371.

5. Rosato V, Guercio V, Bosetti C, et al. Mediterranean diet and colorectal cancer risk: a pooled analysis of three Italian casecontrol studies. Br J Cancer. 2016;115(7):862-5. https://doi.org/ 10.1038/bjc.2016.245.

6. Salas-Salvado J, Bullo M, Babio N, et al. Reduction in the incidence of type 2 diabetes with the Mediterranean diet: results of the PREDIMED-Reus nutrition intervention randomized trial. Diabetes Care. 2011;34(1):14-9. https://doi.org/10.2337/dc101288.

7. Dominguez LJ, Bes-Rastrollo M, de la Fuente-Arrillaga C, et al. Similar prediction of total mortality, diabetes incidence and cardiovascular events using relative- and absolute-component Mediterranean diet score: the SUN cohort. Nutr Metab Cardiovasc Dis NMCD. 2013;23(5):451-8. https://doi.org/10.1016/j. numecd.2011.10.009.

8. Filippatos TD, Panagiotakos DB, Georgousopoulou EN, et al. Mediterranean diet and 10-year (2002-2012) incidence of diabetes and cardiovascular disease in participants with prediabetes: the ATTICA study. Rev Diabet Stud RDS. 2016;13(4):226-35. https://doi.org/10.1900/RDS.2016.13.226.

9. Martinez-Lapiscina EH, Clavero P, Toledo E, et al. Mediterranean diet improves cognition: the PREDIMED-NAVARRA randomised trial. J Neurol Neurosurg Psychiatry. 2013;84(12): 1318-25. https://doi.org/10.1136/jnnp-2012-304792.

10. Galbete C, Toledo E, Toledo JB, et al. Mediterranean diet and cognitive function: the SUN project. J Nutr Health Aging. 2015;19(3):305-12. https://doi.org/10.1007/s12603-015-0441-z.

11. Mayor S. Sixty seconds on... the Mediterranean diet. BMJ (Clin Res Ed). 2018;361:k2667. https://doi.org/10.1136/bmj.k2667. 
12. Estruch R, Ros E, Salas-Salvado J, et al. Primary prevention of cardiovascular disease with a Mediterranean diet supplemented with extra-virgin olive oil or nuts. New Engl J Med. 2018;378(25):e34. https://doi.org/10.1056/NEJMoa1800389.

13. Hodge AM, English DR, Itsiopoulos C, O'Dea K, Giles GG. Does a Mediterranean diet reduce the mortality risk associated with diabetes: evidence from the Melbourne Collaborative Cohort Study. Nutr Metab Cardiovasc Dis NMCD. 2011;21(9):733-9. https://doi.org/10.1016/j.numecd.2010.10.014.

14. Davis C, Hodgson J, Bryan J, Garg M, Woodman R, Murphy K. Older Australians can achieve high adherence to the Mediterranean diet during a 6 month randomised intervention; results from the Medley study. Nutrients. 2017;9(6):534. https://doi. org/10.3390/Nu9060534.

15. Kanauchi M, Kanauchi K. Development of a Mediterranean diet score adapted to Japan and its relation to obesity risk. Food Nutr Res. 2016;60:32172. https://doi.org/10.3402/fnr.v60.32172.

16. Jannasch F, Kroger J, Schulze MB. Dietary patterns and type 2 diabetes: a systematic literature review and meta-analysis of prospective studies. J Nutr. 2017;147(6):1174-82. https://doi. org/10.3945/jn.116.242552.

17. Schwingshackl L, Schwedhelm C, Galbete C, Hoffmann G. Adherence to Mediterranean diet and risk of cancer: an updated systematic review and meta-analysis. Nutrients. 2017;9(10):1063. https://doi.org/10.3390/nu9101063.

18. Davis C, Bryan J, Hodgson J, Murphy K. Definition of the Mediterranean diet: a literature review. Nutrients. 2015;7(11): 9139-53. https://doi.org/10.3390/nu7115459.

19. Sofi F, Macchi C, Abbate R, Gensini GF, Casini A. Mediterranean diet and health status: an updated meta-analysis and a proposal for a literature-based adherence score. Public Health Nutr. 2014;17(12):2769-82. https://doi.org/10.1017/s13689800 13003169.

20. Moher D, Liberati A, Tetzlaff J, Altman DG. Preferred reporting items for systematic reviews and meta-analyses: the PRISMA statement. PLoS Med. 2009;6(7):e1000097. https://doi.org/10. 1371/journal.pmed.1000097.

21. Schwingshackl L, Hoffmann G, Missbach B, Stelmach-Mardas $\mathrm{M}$, Boeing $\mathrm{H}$. An umbrella review of nuts intake and risk of cardiovascular disease. Curr Pharm Des. 2017;23(7):1016-27. https://doi.org/10.2174/1381612822666161010121356.

22. Schwingshackl L, Missbach B, Hoffmann G. An umbrella review of garlic intake and risk of cardiovascular disease. Phytomed Int J Phytother Phytopharmacol. 2016;23(11):1127-33. https://doi. org/10.1016/j.phymed.2015.10.015.

23. Shea BJ, Grimshaw JM, Wells GA, et al. Development of AMSTAR: a measurement tool to assess the methodological quality of systematic reviews. BMC Med Res Methodol. 2007;7(1):10. https://doi.org/10.1186/1471-2288-7-10.

24. Huedo-Medina TB, Garcia M, Bihuniak JD, Kenny A, Kerstetter J. Methodologic quality of meta-analyses and systematic reviews on the Mediterranean diet and cardiovascular disease outcomes: a review. Am J Clin Nutr. 2016;103(3):841-50. https://doi.org/10.3945/ajen.115.112771.

25. U.S. Department of Health and Human Services and U.S. Department of Agriculture. 2015-2020 dietary guidelines for Americans. 8th ed. 2015. https://health.gov/dietaryguidelines/ 2015/guidelines/. Accessed 11 Nov 2017.

26. Schwingshackl L, Knuppel S, Schwedhelm C, et al. Perspective: NutriGrade: a scoring system to assess and judge the meta-evidence of randomized controlled trials and cohort studies in nutrition research. Adv Nutr. 2016;7(6):994-1004. https://doi. org/10.3945/an.116.013052.

27. Trichopoulou A, Costacou T, Bamia C, Trichopoulos D. Adherence to a Mediterranean diet and survival in a Greek population. New Engl J Med. 2003;348(26):2599-608. https://doi.org/10.1056/NEJMoa025039.

28. Dersimonian R, Laird N. Metaanalysis in clinical-trials. Control Clin Trials. 1986;7(3):177-88. https://doi.org/10.1016/01972456(86)90046-2.

29. Riley RD, Higgins JP, Deeks JJ. Interpretation of random effects meta-analyses. BMJ. 2011;342:d549. https://doi.org/10.1136/ bmj.d549.

30. Koloverou E, Esposito K, Giugliano D, Panagiotakos D. The effect of Mediterranean diet on the development of type 2 diabetes mellitus: a meta-analysis of 10 prospective studies and 136,846 participants. Metabolism. 2014;63(7):903-11. https://doi.org/10.1016/j.metabol.2014.04.010.

31. Esposito K, Chiodini P, Maiorino MI, Bellastella G, Panagiotakos D, Giugliano D. Which diet for prevention of type 2 diabetes? A meta-analysis of prospective studies. Endocrine. 2014;47(1):107-16. https://doi.org/10.1007/s12020-014-0264-4.

32. Rosato V, Temple NJ, La Vecchia C, Castellan G, Tavani A, Guercio V. Mediterranean diet and cardiovascular disease: a systematic review and meta-analysis of observational studies. Eur J Nutr. 2017. https://doi.org/10.1007/s00394-017-1582-0.

33. Grosso G, Marventano S, Yang J, et al. A comprehensive metaanalysis on evidence of mediterranean diet and cardiovascular disease: Are individual components equal? Crit Rev Food Sci Nutr. 2017;57(15):3218-32. https://doi.org/10.1080/10408398. 2015.1107021.

34. Martinez-Gonzalez MA, Bes-Rastrollo M. Dietary patterns, Mediterranean diet, and cardiovascular disease. Curr Opin Lipidol. 2014;25(1):20-6. https://doi.org/10.1097/mol.00000 00000000044.

35. Psaltopoulou T, Sergentanis TN, Panagiotakos DB, Sergentanis IN, Kosti R, Scarmeas N. Mediterranean diet, stroke, cognitive impairment, and depression: a meta-analysis. Ann Neurol. 2013;74(4):580-91. https://doi.org/10.1002/ana.23944.

36. Bloomfield HE, Koeller E, Greer N, MacDonald R, Kane R, Wilt TJ. Effects on health outcomes of a mediterranean diet with no restriction on fat intake: a systematic review and metaanalysis. Ann Intern Med. 2016;165(7):491-500. https://doi.org/ 10.7326/m16-0361.

37. Wu L, Sun D. Adherence to Mediterranean diet and risk of developing cognitive disorders: an updated systematic review and meta-analysis of prospective cohort studies. Sci Rep. 2017;7:41317. https://doi.org/10.1038/srep41317.

38. Cao L, Tan L, Wang HF, et al. Dietary patterns and risk of dementia: a systematic review and meta-analysis of cohort studies. Mol Neurobiol. 2016;53(9):6144-54. https://doi.org/10. 1007/s12035-015-9516-4.

39. Singh B, Parsaik AK, Mielke MM, et al. Association of mediterranean diet with mild cognitive impairment and Alzheimer's disease: a systematic review and meta-analysis. J Alzheimer's Dis JAD. 2014;39(2):271-82. https://doi.org/10. 3233/jad-130830.

40. Schwingshackl L, Missbach B, Konig J, Hoffmann G. Adherence to a Mediterranean diet and risk of diabetes: a systematic review and meta-analysis. Public Health Nutr. 2015;18(7):1292-9. https://doi.org/10.1017/s1368980014001542.

41. Agnoli C, Krogh V, Grioni S, et al. A priori-defined dietary patterns are associated with reduced risk of stroke in a large Italian cohort. J Nutr. 2011;141(8):1552-8. https://doi.org/10. 3945/jn.111.140061.

42. Benetou V, Trichopoulou A, Orfanos P, et al. Conformity to traditional Mediterranean diet and cancer incidence: the Greek EPIC cohort. Br J Cancer. 2008;99(1):191-5. https://doi.org/10. 1038/sj.bjc.6604418.

43. de Leon AC, Coello SD, Gonzalez DA, et al. Impaired fasting glucose, ancestry and waist-to-height ratio: main predictors of 
incident diagnosed diabetes in the Canary Islands. Diabet Med. 2012;29(3):399-403. https://doi.org/10.1111/j.1464-5491.2011. 03420.x.

44. Dilis V, Katsoulis M, Lagiou P, Trichopoulos D, Naska A, Trichopoulou A. Mediterranean diet and CHD: the Greek european prospective investigation into cancer and nutrition cohort. Br J Nutr. 2012;108(4):699-709. https://doi.org/10.1017/ s0007114512001821.

45. Lagiou P, Trichopoulos D, Sandin S, et al. Mediterranean dietary pattern and mortality among young women: a cohort study in Sweden. Br J Nutr. 2006;96(2):384-92.

46. Martinez-Gonzalez MA, de la Fuente-Arrillaga C, Nunez-Cordoba JM, et al. Adherence to Mediterranean diet and risk of developing diabetes: prospective cohort study. BMJ (Clinical research ed.). 2008;336(7657):1348-51. https://doi.org/10.1136/ bmj.39561.501007.BE.

47. Martinez-Gonzalez MA, Garcia-Lopez M, Bes-Rastrollo M, et al. Mediterranean diet and the incidence of cardiovascular disease: a Spanish cohort. Nutr Metab Cardiovasc Dis NMCD. 2011;21(4):237-44. https://doi.org/10.1016/j.numecd.2009.10. 005.

48. Martinez-Gonzalez MA, Guillen-Grima F, De Irala J, et al. The Mediterranean diet is associated with a reduction in premature mortality among middle-aged adults. J Nutr. 2012;142(9):1672-8. https://doi.org/10.3945/jn.112.162891.

49. Misirli G, Benetou V, Lagiou P, Bamia C, Trichopoulos D, Trichopoulou A. Relation of the traditional Mediterranean diet to cerebrovascular disease in a Mediterranean population. Am J Epidemiol. 2012;176(12):1185-92. https://doi.org/10.1093/aje/ kws205.

50. Rossi M, Turati F, Lagiou P, et al. Mediterranean diet and glycaemic load in relation to incidence of type 2 diabetes: results from the Greek cohort of the population-based European prospective investigation into cancer and nutrition (EPIC). Diabetologia. 2013;56(11):2405-13. https://doi.org/10.1007/ s00125-013-3013-y.

51. Chan R, Chan D, Woo J. The association of a priori and a posterior dietary patterns with the risk of incident stroke in Chinese older people in Hong Kong. J Nutr Health Aging. 2013;17(10):866-74. https://doi.org/10.1007/s12603-013-0334$\mathrm{y}$.

52. Tong TY, Wareham NJ, Khaw KT, Imamura F, Forouhi NG. Prospective association of the Mediterranean diet with cardiovascular disease incidence and mortality and its population impact in a non-Mediterranean population: the EPIC-Norfolk study. BMC Med. 2016;14(1):135. https://doi.org/10.1186/ s12916-016-0677-4.

53. Couto E, Boffetta $\mathrm{P}$, Lagiou $\mathrm{P}$, et al. Mediterranean dietary pattern and cancer risk in the EPIC cohort. $\mathrm{Br} \mathrm{J}$ Cancer. 2011;104(9):1493-9. https://doi.org/10.1038/bjc.2011.106.

54. Couto E, Sandin S, Lof M, Ursin G, Adami HO, Weiderpass E. Mediterranean dietary pattern and risk of breast cancer. PLoS One. 2013;8(2):e55374. https://doi.org/10.1371/journal.pone. 0055374.

55. Bamia C, Lagiou P, Buckland G, et al. Mediterranean diet and colorectal cancer risk: results from a European cohort. Eur J Epidemiol. 2013;28(4):317-28. https://doi.org/10.1007/s10654013-9795-x.

56. Gardener $\mathrm{H}$, Wright $\mathrm{CB}, \mathrm{Gu} \mathrm{Y}$, et al. Mediterranean-style diet and risk of ischemic stroke, myocardial infarction, and vascular death: the Northern Manhattan Study. Am J Clin Nutr. 2011;94(6):1458-64. https://doi.org/10.3945/ajcn.111.012799.

57. Cuenca-Garcia M, Artero EG, Sui X, Lee DC, Hebert JR, Blair $\mathrm{SN}$. Dietary indices, cardiovascular risk factors and mortality in middle-aged adults: findings from the Aerobics Center
Longitudinal Study. Ann Epidemiol. 2014;24(4):297-303.e2. https://doi.org/10.1016/j.annepidem.2014.01.007.

58. Buckland G, Agudo A, Lujan L, et al. Adherence to a Mediterranean diet and risk of gastric adenocarcinoma within the European Prospective Investigation into Cancer and Nutrition (EPIC) cohort study. Am J Clin Nutr. 2010;91(2):381-90. https://doi.org/10.3945/ajen.2009.28209.

59. Buckland G, Agudo A, Travier N, et al. Adherence to the Mediterranean diet reduces mortality in the Spanish cohort of the European Prospective Investigation into Cancer and Nutrition (EPIC-Spain). Br J Nutr. 2011;106(10):1581-91. https://doi. org/10.1017/S0007114511002078.

60. Buckland G, Gonzalez CA, Agudo A, et al. Adherence to the Mediterranean diet and risk of coronary heart disease in the Spanish EPIC Cohort Study. Am J Epidemiol. 2009;170(12):1518-29. https://doi.org/10.1093/aje/kwp282.

61. InterAct C, Romaguera D, Guevara M, et al. Mediterranean diet and type 2 diabetes risk in the European Prospective Investigation into Cancer and Nutrition (EPIC) study: the InterAct project. Diabetes Care. 2011;34(9):1913-8. https://doi.org/10. 2337/dc11-0891.

62. Buckland G, Travier N, Cottet V, et al. Adherence to the mediterranean diet and risk of breast cancer in the European prospective investigation into cancer and nutrition cohort study. Int J Cancer. 2013;132(12):2918-27. https://doi.org/10.1002/ijc. 27958.

63. Roberts RO, Geda YE, Cerhan JR, et al. Vegetables, unsaturated fats, moderate alcohol intake, and mild cognitive impairment. Dement Geriatr Cogn Disord. 2010;29(5):413-23. https://doi. org/10.1159/000305099.

64. Scarmeas N, Stern Y, Mayeux R, Manly JJ, Schupf N, Luchsinger JA. Mediterranean diet and mild cognitive impairment. Arch Neurol. 2009;66(2):216-25. https://doi.org/10.1001/arch neurol.2008.536.

65. Scarmeas N, Stern Y, Tang MX, Mayeux R, Luchsinger JA. Mediterranean diet and risk for Alzheimer's disease. Ann Neurol. 2006;59(6):912-21. https://doi.org/10.1002/ana.20854.

66. Feart C, Samieri C, Rondeau V, et al. Adherence to a Mediterranean diet, cognitive decline, and risk of dementia. JAMA. 2009;302(6):638-48. https://doi.org/10.1001/jama.2009. 1146.

67. Tsivgoulis G, Psaltopoulou T, Wadley VG, et al. Adherence to a Mediterranean diet and prediction of incident stroke. Stroke. 2015;46(3):780-5. https://doi.org/10.1161/strokeaha.114. 007894.

68. Lassale C, Gunter MJ, Romaguera D, et al. Diet quality scores and prediction of all-cause, cardiovascular and cancer mortality in a Pan-European cohort study. PLoS One. 2016;11(7):e0159025. https://doi.org/10.1371/journal.pone. 0159025.

69. Bosire C, Stampfer MJ, Subar AF, et al. Index-based dietary patterns and the risk of prostate cancer in the NIH-AARP diet and health study. Am J Epidemiol. 2013;177(6):504-13. https://doi.org/10.1093/aje/kws261.

70. Fung TT, Hu FB, McCullough ML, Newby PK, Willett WC, Holmes MD. Diet quality is associated with the risk of estrogen receptor-negative breast cancer in postmenopausal women. J Nutr. 2006;136(2):466-72.

71. Fung TT, Rexrode KM, Mantzoros CS, Manson JE, Willett WC, $\mathrm{Hu}$ FB. Mediterranean diet and incidence of and mortality from coronary heart disease and stroke in women. Circulation. 2009;119(8):1093-100. https://doi.org/10.1161/circulationaha. 108.816736.

72. George SM, Ballard-Barbash R, Manson JE, et al. Comparing indices of diet quality with chronic disease mortality risk in postmenopausal women in the Women's Health Initiative 
Observational Study: evidence to inform national dietary guidance. Am J Epidemiol. 2014;180(6):616-25. https://doi.org/10. 1093/aje/kwu173.

73. Harmon BE, Boushey CJ, Shvetsov YB, et al. Associations of key diet-quality indexes with mortality in the Multiethnic Cohort: the Dietary Patterns Methods Project. Am J Clin Nutr. 2015;101(3):587-97. https://doi.org/10.3945/ajcn.114.090688.

74. Jacobs S, Harmon BE, Boushey CJ, et al. A priori-defined diet quality indexes and risk of type 2 diabetes: the Multiethnic Cohort. Diabetologia. 2015;58(1):98-112. https://doi.org/10. 1007/s00125-014-3404-8.

75. Reedy J, Krebs-Smith SM, Miller PE, et al. Higher diet quality is associated with decreased risk of all-cause, cardiovascular disease, and cancer mortality among older adults. J Nutr. 2014;144(6):881-9. https://doi.org/10.3945/jn.113.189407.

76. Tobias DK, Hu FB, Chavarro J, Rosner B, Mozaffarian D, Zhang C. Healthful dietary patterns and type 2 diabetes mellitus risk among women with a history of gestational diabetes mellitus. Arch Intern Med. 2012;172(20):1566-72. https://doi.org/ 10.1001/archinternmed.2012.3747.

77. Sotos-Prieto M, Bhupathiraju SN, Mattei J, et al. Changes in diet quality scores and risk of cardiovascular disease among US men and women. Circulation. 2015;132(23):2212-9. https://doi.org/ 10.1161/circulationaha.115.017158.

78. Mitrou PN, Kipnis V, Thiebaut AC, et al. Mediterranean dietary pattern and prediction of all-cause mortality in a US population: results from the NIH-AARP Diet and Health Study. Arch Intern Med. 2007;167(22):2461-8. https://doi.org/10.1001/archinte. 167.22.2461.

79. de Koning L, Chiuve SE, Fung TT, Willett WC, Rimm EB, Hu FB. Diet-quality scores and the risk of type 2 diabetes in men. Diabetes Care. 2011;34(5):1150-6. https://doi.org/10.2337/ dc10-2352.

80. Lopez-Garcia E, Rodriguez-Artalejo F, Li TY, et al. The Mediterranean-style dietary pattern and mortality among men and women with cardiovascular disease. Am J Clin Nutr. 2014;99(1):172-80. https://doi.org/10.3945/ajcn.113.068106.

81. Haring B, Wu C, Mossavar-Rahmani Y, et al. No association between dietary patterns and risk for cognitive decline in older women with 9-year follow-up: data from the Women's Health Initiative Memory Study. J Acad Nutr Diet. 2016;116(6):921-930.e1. https://doi.org/10.1016/j.jand.2015.12. 017.

82. Abiemo EE, Alonso A, Nettleton JA, et al. Relationships of the Mediterranean dietary pattern with insulin resistance and diabetes incidence in the Multi-Ethnic Study of Atherosclerosis (MESA). Br J Nutr. 2013;109(8):1490-7. https://doi.org/10. 1017/s0007114512003339.

83. Mozaffarian D, Marfisi R, Levantesi G, et al. Incidence of newonset diabetes and impaired fasting glucose in patients with recent myocardial infarction and the effect of clinical and lifestyle risk factors. Lancet. 2007;370(9588):667-75. https://doi. org/10.1016/s0140-6736(07)61343-9.

84. Vormund K, Braun J, Rohrmann S, Bopp M, Ballmer P, Faeh D. Mediterranean diet and mortality in Switzerland: An alpine paradox? Eur J Nutr. 2015;54(1):139-48. https://doi.org/10. 1007/s00394-014-0695-y.

85. Hoevenaar-Blom MP, Nooyens AC, Kromhout D, et al. Mediterranean style diet and 12-year incidence of cardiovascular diseases: the EPIC-NL cohort study. PLoS One. 2012;7(9):e45458. https://doi.org/10.1371/journal.pone. 0045458 .

86. Hoevenaar-Blom MP, Spijkerman AM, Boshuizen HC, Boer JM, Kromhout D, Verschuren WM. Effect of using repeated measurements of a Mediterranean style diet on the strength of the association with cardiovascular disease during 12 years: the
Doetinchem Cohort Study. Eur J Nutr. 2014;53(5):1209-15. https://doi.org/10.1007/s00394-013-0621-8.

87. Sjogren P, Becker W, Warensjo E, et al. Mediterranean and carbohydrate-restricted diets and mortality among elderly men: a cohort study in Sweden. Am J Clin Nutr. 2010;92(4):967-74. https://doi.org/10.3945/ajcn.2010.29345.

88. Olsson E, Karlstrom B, Kilander L, Byberg L, Cederholm T, Sjogren P. Dietary patterns and cognitive dysfunction in a 12-year follow-up study of 70 year old men. J Alzheimer' Dis JAD. 2015;43(1):109-19. https://doi.org/10.3233/jad-140867.

89. Tognon G, Lissner L, Saebye D, Walker KZ, Heitmann BL. The Mediterranean diet in relation to mortality and CVD: a Danish cohort study. Br J Nutr. 2014;111(1):151-9. https://doi.org/10. 1017/s0007114513001931.

90. Bertoia ML, Triche EW, Michaud DS, et al. Mediterranean and dietary approaches to stop hypertension dietary patterns and risk of sudden cardiac death in postmenopausal women. Am J Clin Nutr. 2014;99(2):344-51. https://doi.org/10.3945/ajcn.112. 056135 .

91. Tektonidis TG, Akesson A, Gigante B, Wolk A, Larsson SC. A Mediterranean diet and risk of myocardial infarction, heart failure and stroke: a population-based cohort study. Atherosclerosis. 2015;243(1):93-8. https://doi.org/10.1016/j.ath erosclerosis.2015.08.039.

92. Bellavia A, Tektonidis TG, Orsini N, Wolk A, Larsson SC. Quantifying the benefits of Mediterranean diet in terms of survival. Eur J Epidemiol. 2016;31(5):527-30. https://doi.org/10. 1007/s10654-016-0127-9.

93. Yau WY, Hankey GJ. Which dietary and lifestyle behaviours may be important in the aetiology (and prevention) of stroke? J Clin Neurosci Off J Neurosurg Soc Australas. 2011;18(1):76-80. https://doi.org/10.1016/j.jocn.2010.05.014.

94. Whalen KA, Judd S, McCullough ML, Flanders WD, Hartman TJ, Bostick RM. Paleolithic and Mediterranean diet pattern scores are inversely associated with all-cause and cause-specific mortality in adults. J Nutr. 2017;147(4):612-20. https://doi.org/ 10.3945/jn.116.241919.

95. Morris MC, Tangney CC, Wang Y, Sacks FM, Bennett DA, Aggarwal NT. MIND diet associated with reduced incidence of Alzheimer's disease. Alzheimer's Dement J Alzheimer's Assoc. 2015;11(9):1007-14. https://doi.org/10.1016/j.jalz.2014.11.009.

96. Knoops KT, de Groot LC, Kromhout D, et al. Mediterranean diet, lifestyle factors, and 10-year mortality in elderly European men and women: the HALE project. JAMA. 2004;292(12):1433-9. https://doi.org/10.1001/jama.292.12. 1433.

97. Agnoli C, Grioni S, Sieri S, et al. Italian Mediterranean Index and risk of colorectal cancer in the Italian section of the EPIC cohort. Int J Cancer. 2013;132(6):1404-11. https://doi.org/10. 1002/ijc. 27740.

98. Brunner EJ, Mosdol A, Witte DR, et al. Dietary patterns and 15 -y risks of major coronary events, diabetes, and mortality. Am J Clin Nutr. 2008;87(5):1414-21.

99. Menotti A, Alberti-Fidanza A, Fidanza F, Lanti M, Fruttini D. Factor analysis in the identification of dietary patterns and their predictive role in morbid and fatal events. Public Health Nutr. 2012;15(7):1232-9. s1368980011003235.

100. Tognon G, Nilsson LM, Lissner L, et al. The Mediterranean diet score and mortality are inversely associated in adults living in the subarctic region. J Nutr. 2012;142(8):1547-53. https://doi. org/10.3945/jn.112.160499.

101. Chiuve SE, Fung TT, Rimm EB, et al. Alternative dietary indices both strongly predict risk of chronic disease. J Nutr. 2012;142(6):1009-18. https://doi.org/10.3945/jn.111.157222. 
102. Mursu J, Steffen LM, Meyer KA, Duprez D, Jacobs DR Jr. Diet quality indexes and mortality in postmenopausal women: the Iowa Women's Health Study. Am J Clin Nutr. 2013;98(2):444-53. https://doi.org/10.3945/ajcn.112.055681.

103. Chrysohoou C, Panagiotakos DB, Aggelopoulos P, et al. The Mediterranean diet contributes to the preservation of left ventricular systolic function and to the long-term favorable prognosis of patients who have had an acute coronary event. Am J Clin Nutr. 2010;92(1):47-54. https://doi.org/10.3945/ajen.2009. 28982.

104. Panagiotakos DB, Pitsavos C, Chrysohoou C, Skoumas I, Stefanadis C, Study A. Five-year incidence of cardiovascular disease and its predictors in Greece: the ATTICA study. Vasc Med. 2008;13(2):113-21. https://doi.org/10.1177/1358863x07087731.

105. Menotti A, Alberti-Fidanza A, Fidanza F. The association of the Mediterranean Adequacy Index with fatal coronary events in an Italian middle-aged male population followed for 40 years. Nutr Metab Cardiovasc. 2012;22(4):369-75. https://doi.org/10.1016/ j.numecd.2010.08.002.

106. Tsivgoulis G, Judd S, Letter AJ, et al. Adherence to a Mediterranean diet and risk of incident cognitive impairment. Neurology. 2013;80(18):1684-92. https://doi.org/10.1212/ WNL.0b013e3182904f69.

107. Benisi-Kohansal S, Saneei P, Salehi-Marzijarani M, Larijani B, Esmaillzadeh A. Whole-grain intake and mortality from all causes, cardiovascular disease, and cancer: a systematic review and dose-response meta-analysis of prospective cohort studies. Adv Nutr. 2016;7(6):1052-65. https://doi.org/10.3945/an.115. 011635 .

108. Zhang B, Zhao Q, Guo W, Bao W, Wang X. Association of whole grain intake with all-cause, cardiovascular, and cancer mortality: a systematic review and dose-response meta-analysis from prospective cohort studies. Eur J Clin Nutr. 2017. https://doi.org/10.1038/ejcn.2017.149.

109. Lu W, Chen H, Niu Y, Wu H, Xia D, Wu Y. Dairy products intake and cancer mortality risk: a meta-analysis of 11 population-based cohort studies. Nutr J. 2016;15(1):91. https://doi.org/10.1186/s12937-016-0210-9.

110. WCRF. Cancer Facts Figures. World Cancer Research Fund International London. 2017.

111. Schwingshackl L, Schwedhelm C, Hoffmann G, et al. Food groups and risk of colorectal cancer. Int $\mathrm{J}$ Cancer. 2018;142(9):1748-58. https://doi.org/10.1002/ijc.31198.

112. Seal CJ, Brownlee IA. Whole-grain foods and chronic disease: evidence from epidemiological and intervention studies. Proc Nutr Soc. 2015;74(3):313-9. https://doi.org/10.1017/ S0029665115002104.

113. Aune D, Keum N, Giovannucci E, et al. Whole grain consumption and risk of cardiovascular disease, cancer, and all cause and cause specific mortality: systematic review and doseresponse meta-analysis of prospective studies. BMJ. 2016;353:i2716. https://doi.org/10.1136/bmj.i2716.

114. Ekmekcioglu C, Wallner P, Kundi M, Weisz U, Haas W, Hutter HP. Red meat, diseases, and healthy alternatives: a critical review. Crit Rev Food Sci Nutr. 2018;58(2):247-61. https://doi. org/10.1080/10408398.2016.1158148.

115. Bechthold A, Boeing H, Schwedhelm C, et al. Food groups and risk of coronary heart disease, stroke and heart failure: a systematic review and dose-response meta-analysis of prospective studies. Critical Rev Food Sci Nutr. 2017. https://doi.org/10. 1080/10408398.2017.1392288.

116. Schwingshackl L, Hoffmann G, Lampousi A-M, Knüppel S, Iqbal K, Schwedhelm C, Bechthold A, Schlesinger S, Boeing H. Food groups and risk of type 2 diabetes mellitus: a systematic review and meta-analysis of prospective studies. Eur J Epidemiol. 2017;32(5):363-75.

117. Bach-Faig A, Berry EM, Lairon D, Reguant J, Trichopoulou A, Dernini S, Medina FX, Battino M, Belahsen R, Miranda G, Serra-Majem L. Mediterranean diet pyramid today. Science and cultural updates. Public Health Nutr. 2011;14(12A):2274-84. 